\title{
The Effect of STEAM-based Learning on Students' Concept Mastery and Creativity in Learning Light and Optics
}

\author{
Gita Ayu Wandari¹, Agus Fany Chandra Wijaya², Rika Rafikah Agustin ${ }^{*}$ \\ ${ }^{1}$ International Program on Science Education, Faculty of Mathematics and Science Education, Universitas Pendidikan Indonesia, \\ Indonesia \\ ${ }^{2}$ Departement of Physics Education, Faculty of Mathematics and Science Education, Universitas Pendidikan Indonesia, Indonesia \\ *Corresponding Author. rikarafikah@upi.edu
}

\begin{abstract}
The integrated knowledge should be implemented to face the $21^{\text {st }}$-century era. Beside the integrated knowledge, mastery the concept and creativity also must be involved in order to enhance the quality of education. Thus, this research was aimed to investigate the effect of STEAM-Based Learning on Students' Concept Mastery and Creativity in learning Light and Optics. The method that used was a mixed method with convergent parallel design. The population in this research was $8^{\text {th }}$-grade students in private junior high school in West Bandung and the sample was one class of $8^{\text {th }}$ grade. The school implemented Indonesian Curriculum 2013 in the teaching-learning process. The sampling techniques were convenience sampling. The number of participants in this research was 27 students. The quantitative data in this research was obtained through an objective test. The objective test was made based on Bloom's Taxonomy revision by Anderson. The qualitative data was obtained through the creativity rubric adopted from Creative Product Semantic Scale (CPSS) developed by O'Quinn and Bessemer. The dimension that was in creativity is novelty, resolution, and elaboration and synthesis. According to the research, students' concept mastery improved as much as 0.78 with category high improvement after the implementation of STEAM-Based Learning. For students' creativity achievement, in every dimension gained different result: 1) Novelty is categorized into good with 75.6\%, 2) Resolution is categorized into good with $77.8 \%$, and 3 ) Elaboration and synthesis are categorized into enough with $65.3 \%$. Overall, students' concept mastery and creativity in the implementation of STEAM-Based Learning in learning light and optic is categorized as good.
\end{abstract}

Keywords STEAM-Based Learning, Students’ Concept Mastery, Students’ Creativity, Light and Optics

\section{INTRODUCTION}

The new paradigm of the $21^{\text {st }}$ Century science education explores a wide range of possibilities that can foster students' interest in science and creative convergent thinking. In Indonesia, education is supported by the National Curriculum of 2013. The purpose of using National Curriculum 2013 is to prepare Indonesian to be a creative, productive, innovative, affective, and also give a contribution to the environment, country, and the world. STEAM (science, technology, engineering, art, and mathematics) education has been implemented to enhance scientific literacy to use the integrated knowledge in the newly revised Korean science education curriculum (Kong \& Huo, 2014). Recently STEAM education has emerged to develop human resource with creativity in mind and see and understand human society in the future. STEAM education is defined as education in which the students' understanding and interest in related subjects such as science, technology, engineering, etc., foster of conversions of thinking and problem solving based on science and technology (Baek \& Yoon, 2016). Hence, the purpose of National Curriculum 2103 of Indonesia and STEAM has the similarity which is to make the student be creative and implement the knowledge in daily life.

Learning activities cannot be separated from the mastery concept. Ability in mastering the material can be seen from the mastery concept. Mastery concept is the students' ability to understand the meaning of learning and apply it in their daily life (Shidiq, Rochintaniawati, \& Sanjaya, 2017). Mastery concept is very important, Anderson and Krathwohl (2001) state that mastery concept can improve their intellectual skills and help them solve the problem they face and lead them to meaningful learning.

Received: 6 September 2018

Revised: 16 December 2018

Published: 18 December 2018 
Concept Mastery should be completed by creativity and other skills to enhance the quality of students. Deep understanding of a concept is highly needed to maximize the students' creativity. Creativity has long been recognized as a powerful force in shaping human society progress and knowledge (Henriksen, Mishra, \& Fisser, 2016). Creativity and innovation concern to the process of creating and applying new knowledge (Gurteen, 1998).

Concept mastery not only should be completed with the creativity but also should be related or implemented in daily life. Light and optics is something that used in daily life. It is an essential concept that student is difficult to understand. Light and optics concept is a complex area for students and if it is not connected even implemented to daily life the student may not grasp the concept easily. The concept of light and optics is a relay on daily life such as camera, microscope, telescope, etc. The concept of the optic can be developed to make a valuable product in the future. This concept consists of science and mathematical explanation. Besides, it also could be integrated with technology, engineering, and art to produce a better product. Light and optics topic also in line with STEAM and National Curriculum 2013 of Indonesia because the topic makes the student be a creative one to make something useful in daily life.

Thus, the present study proposed the research to see the effect of STEAM-Based Learning on Students' Concept Mastery and Students' Creativity in Learning Light and Optics. This research will analyze two variables they are students' concept mastery and students' creativity towards STEAM-Based Learning.

\section{METHOD}

The research method used in this research is the Mixed Method. According to Creswell (2012) stated that mixed method is a type of research design which collects, analyzes, and mixes both quantitative and qualitative methods in a single study or series of studies to understand research problem. The quantitative data focuses on students' concept mastery that is measured by an objective test in form multiple choices test while the qualitative analysis focuses on students' creativity that is measured by the rubric of CPSS developed by O'Quin and Bessemer (2006). There are several sub aspects in CPSS rubric. After the students finish their project, the researcher gives a score to the project done by the student and find the average of the score. All data are analyzed separately based on the indicator and compared to obtain better understanding and interpretation regarding the effect of STEAM-Based Learning on students' concept mastery and creativity in learning light and optics. Then, the researcher finds the gain to see the improvement of a student using STEAM Based Learning. Besides, the researcher relates the result of the concept mastery and creativity and find the relation of both variables.
The location of this research was in Private Junior High School in Bandung. The school was using Indonesian Curriculum 2013 in the teaching-learning process. Babasa Indonesia was the daily language used. The population in this research are $8^{\text {th }}$ students in Private Junior High School. The researcher took one class in eight grades as the sample consist of 27 students.

The sampling technique was convenience sampling technique. Fraenkel, Wallen, and Hyun (2013) stated that convenience technique is used because there is a group of individuals who (conveniently) are available for study (Fraenkel, Wallen, \& Hyun, 2013). the research problem and question rather than only a method (Creswell, 2012).

Based on the research method which has been adjusted to the research objective, therefore the research design which was implemented in this research is the convergent parallel design. The rationale for this design is to complete the understanding of research problem result from collecting both quantitative and qualitative data at the same time (Creswell, 2012). Besides researcher chose one class to make the researcher easier to conduct the research. The school has 3 classes of 8 grade. The researcher selected one class of 27 students because compare to the other classes, it was the available class and the amount of the student is not too much.

In this research, the concept of Light and Optics is limited by Core Competence No. 3 and Basic Competence No 3.12 and 4.12 that are attached in Kurikulum 2013. The focus of subtopics that will be investigated by students such as (1) Light properties, (2) The image formation of lenses, and (3) Telescope.

There are two types of instruments used in this research. There are objective test and rubric. First, an objective test based on Bloom's Revised Edition was used to measure students' concept mastery before and after implementing STEAM-Based Learning. It consists of Pretest and Post-test. A pre-test is conducted to find the prior knowledge, while the post-test is conducted to identify whether the cognitive mastery is increasing or not. The cognitive level that will be tested in this objective test is C4 (analyzing), C5 (evaluating), and C6 (Creating).

Concept mastery test consists of forty-one questions before judgment by experts. It is used to measure students' concept mastery. After judging by the expert the objective is only twenty questions as a representative for each learning indicators. Then, the test was distributed to students in grade 8 as a test. The next step after conducting the test, the result is analyzed the objective test using ANATES software to measure the validity, reliability, difficulty level, discriminating power and distractor. Second, Creative Product Semantic Scale (CPSS) developed by Besemer and Treffinger (1981) was adapted to analyze students' creativity. This analysis was used to assess students' product at the end of the class. The 
Table 1 The result of students' concept mastery

\begin{tabular}{lllllll}
\hline No & Component & $\begin{array}{l}\text { Pre- } \\
\text { test }\end{array}$ & $\begin{array}{l}\text { Post- } \\
\text { test }\end{array}$ & G & $<$ g $>$ & $\begin{array}{l}\text { Cate- } \\
\text { gory }\end{array}$ \\
\hline 1 & Participant & 27 & 27 & & & \\
2 & Average & 43 & 87 & & & \\
3 & Lowest & 15 & 70 & 44.26 & 0.78 & High \\
& $\begin{array}{l}\text { Score } \\
4\end{array}$ & & & & & \\
& Highest & 70 & 100 & & & \\
& Score & & & & & \\
\hline
\end{tabular}

adapted rubric of CPSS constructed by the author has been judged by two experts.

\section{RESULT AND DISCUSSION}

The results show quantitative and qualitative data. The pre-test and the post-test are conducted to determine the students' concept mastery before and after treatments. Qualitative analysis will describe the students' product of the project at the end of the class.

\subsection{Students' Concept Mastery}

The profile of students' concept mastery was obtained from objective test consisted of 20 multiple choice question that has been given as pre-test and post-test while implementing STEAM-Based Learning in chapter light and optics. The test item has been tested in term of validity, reliability, discriminating power, and difficulty level. Besides, it also has been judged by some experts and revised so it is appropriate to be used as a research instrument to obtain the data of students' concept mastery.

The improvement of students' concept mastery is determined by the calculation of the normalized gain $<\mathrm{g}>$. Normalized gain is calculation processed through data of pre-test and a post-test score of students. The result is presented in Table 1. The average of the pre-test conducted before the implementation of STEAM-Based Learning is 43.14 and it is improving into 87.40 in the post-test. For the score of the students, the lower score of the student in pre-test is 15 and the highest is 70 . Merely, the lower score of post-tests is 70 and the highest is 100 . To get the improvement score, a normalized gain $<\mathrm{g}>$ was calculated. Based on the result, the students' concept mastery is improving with the normalized score 0.78 that assume as high improvement according to Hake (1998).

In order to analyze the profile of students' concept mastery, the improvement of each test item in every cognitive domain should be processed. The test item used in this research was developed based on the Bloom' Taxonomy Revision by Anderson and Krathwohl (2001). There are three levels considered to be used in this research based on the basic competence that is used. Those are analyzing (C4), evaluation (C5), and creating (C6). The result is presented in Table 2 .

In order to analyze the improvement of concept mastery in each group, the test item was analyzed based on

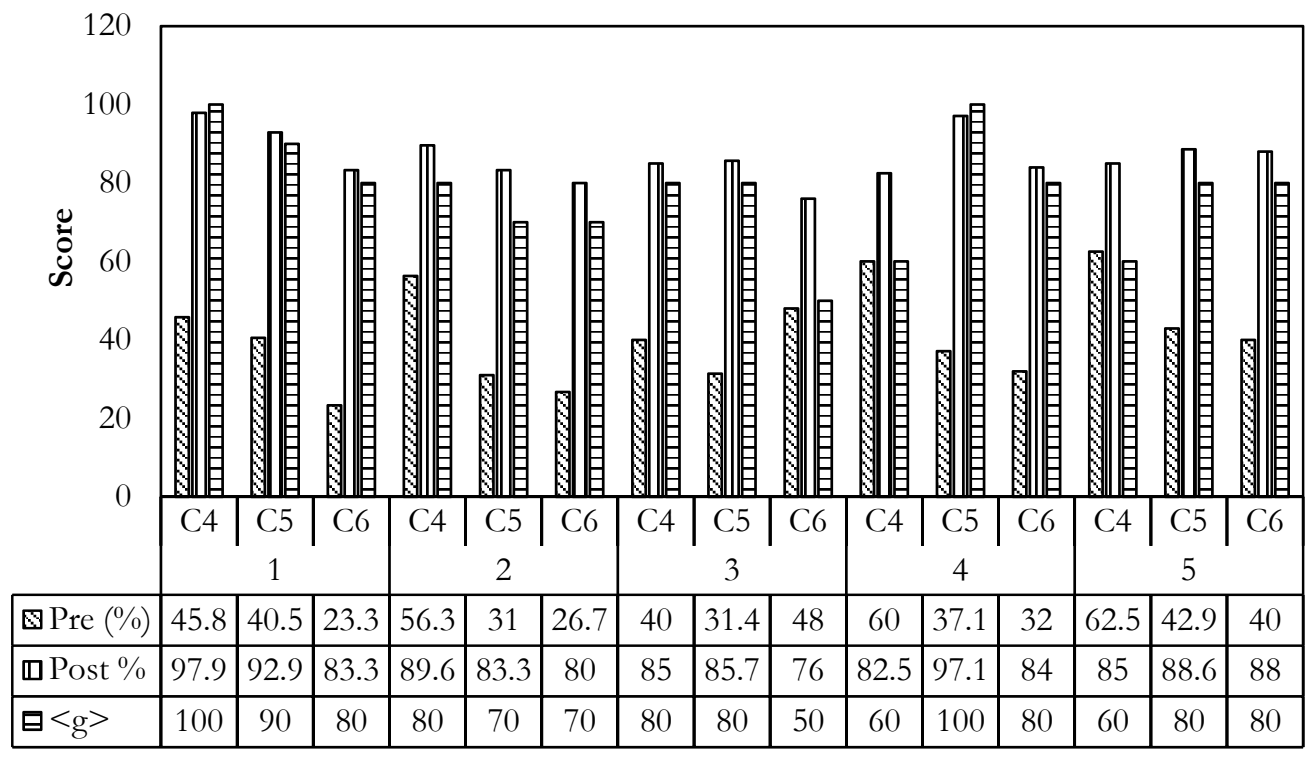

Cognitive Level of Group

Figure 1 Concept mastery's improvement of each group

Table 2 The summary of students' concept mastery based on Bloom' Taxonomy Revised Edition

\begin{tabular}{|c|c|c|c|c|c|c|c|}
\hline \multirow{2}{*}{$\begin{array}{c}\text { Cognitive } \\
\text { Domain }\end{array}$} & \multirow{2}{*}{$\begin{array}{l}\text { Amount of } \\
\text { Question }\end{array}$} & \multirow{2}{*}{$\begin{array}{l}\text { Number of } \\
\text { Students }\end{array}$} & \multicolumn{2}{|c|}{ Average Score } & \multirow{2}{*}{ G } & \multirow{2}{*}{$<\mathrm{g}>$} & \multirow{2}{*}{ Category } \\
\hline & & & Pre-test & Post-test & & & \\
\hline C4 & 8 & 27 & 52.8 & 88.4 & 35.6 & 0.75 & High \\
\hline C5 & 7 & 27 & 36.5 & 89.4 & 52.9 & 0.83 & High \\
\hline C6 & 5 & 27 & 33.3 & 82.2 & 48.9 & 0.73 & High \\
\hline
\end{tabular}


the students' group. The result of each cognitive domain in each group is presented in Figure 1.

The result of STEAM-Based Learning implementation shows the average of pre-test is 43.35 , meanwhile the average of post-test is 87.42. it is showing the improvement of concept mastery by processed the pre-test and post-test results the gain as much as 44.26. In order to categorize the students' concept mastery improvement, the normalized gain is used. The result of the normalized gain is 0.78 which is categorized as a high improvement. Therefore, the hypothesis is accepted that STEAM-Based Learning improves students' concept mastery. This result is supported by previous findings by Kim, Ko, Han, and Hong (2014) that is STEAM education influenced the improvement of academic achievement, creative problemsolving abilities, and scientific attitude. The research compared the control and experimental group in post-test and analyze it quantitatively and found out there is differences in the results.

Another research by Kim and Park (2012) resulted that the STEAM Teaching Model is stimulated the students understanding related the activities in STEAM itself. Henriksen (2014) also stated in their research that STEAM Education significantly influenced the improvement of academic achievement, basic scientific process skills, and affective domain. This result showed the improvement of students' assessment in content knowledge from 30\% to $40 \%$.

The instrument was arrange based on Bloom's Taxonomy revised edition by Anderson and Krathwohl (2001). There is three cognitive levels used in this research which is analyzing (C4), evaluating (C5), and creating (C6). The result shows that $\mathrm{n}$-gain for $\mathrm{C} 4$ level is 0.78 which categorized as high, C5 level is 0.83 which categorized as high, and C6 level is 0.73 which categorized as high. The higher value of $n$-gain is evaluating (C5). The result shows the students are easier to checking, critiquing, testing something, or making a judgment.

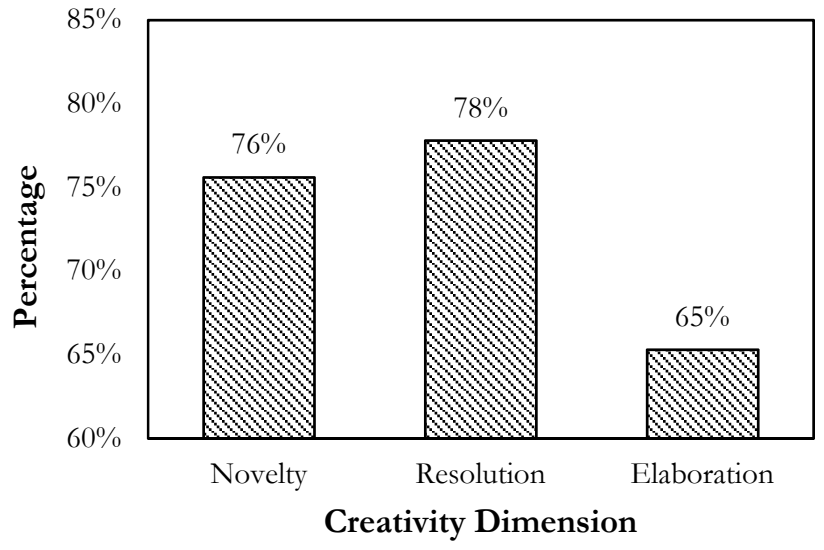

Figure 2 Result of creativity dimension

DOI: $10.17509 / j s l . v 2 i 1.12878$
Light and optics are though in Indonesian Curriculum 2013 and it delivered when implementation of STEAMBased Learning. In the process of the implementation, the students find a problem in learning light and optics. They said the topic is too abstract and many concepts deliver in this chapter. The strategy of the teacher to make the student understand the topic is to divide the class into groups and give them a problem related to the concept. The students are pro-active. They always ask the question outside the class if they do not understand the concept. The students have high curiosity makes the students give more attention while the implementation.

There are steps of STEAM-Based Learning implemented in this research. There are 3 steps, those are 1) presentation of the situation; 2) creative design; 3) emotional experience. The first steps implemented at the beginning of the meeting until all the concept has been delivered to make the student understand the relationship between the concept and real life (Baek \& Yoon, 2016).

Compare to the other method, in Pratiwi, Rochintaniawati, \& Agustin (2018) stated that the improvement of students' concept mastery after implemented the multiple intelligent-based learning resulted in medium improvement as much as 0.61 . hence, every method will have a different result.

\subsection{Students' Creativity}

In this research, students' creativity is measured by telescope they made as a final project. Students' creativity is assessed by using CPSS rubric adapted from Besemer and Treffinger (1981). Besemer and Treffinger (1981) suggested that product creativity is grouped into three creative dimensions which are novelty, resolution, and elaboration and synthesis. Each aspect has several criteria and also sub-criteria to make easier to assess the product of creativity.

The criteria of novelty used are original, germinal, and surprising; for the resolution are valuable, logic, and useful; and the last, resolution and synthesis are organic, wellcrafted, elegant, understandable, and complex. The result of creativity is stated in Figure 2.

Figure 2 presents the result of every creativity dimension. For novelty dimension is $75.6 \%$, resolution dimension is $77.8 \%$, and elaboration is $65.3 \%$. In order to see the whole profile of creativity in each group, the creativity in each group is necessary to be processed. The category of all dimensions is good. The students were more attractive and excited when they make the project. Every group has a good collaboration because every group consists of the students who have the same characteristic, thus they enjoyed when making the project. The result of the creativity in each group is presented in Figure 3.

Based on Figure 3, every dimension in each group has a different result. Group 1 got $89 \%$ for novelty, $56 \%$ for resolution, and $73 \%$ for elaboration in average $73 \%$. Group 2 got $100 \%$ for novelty, $89 \%$ for resolution, and $93 \%$ for 


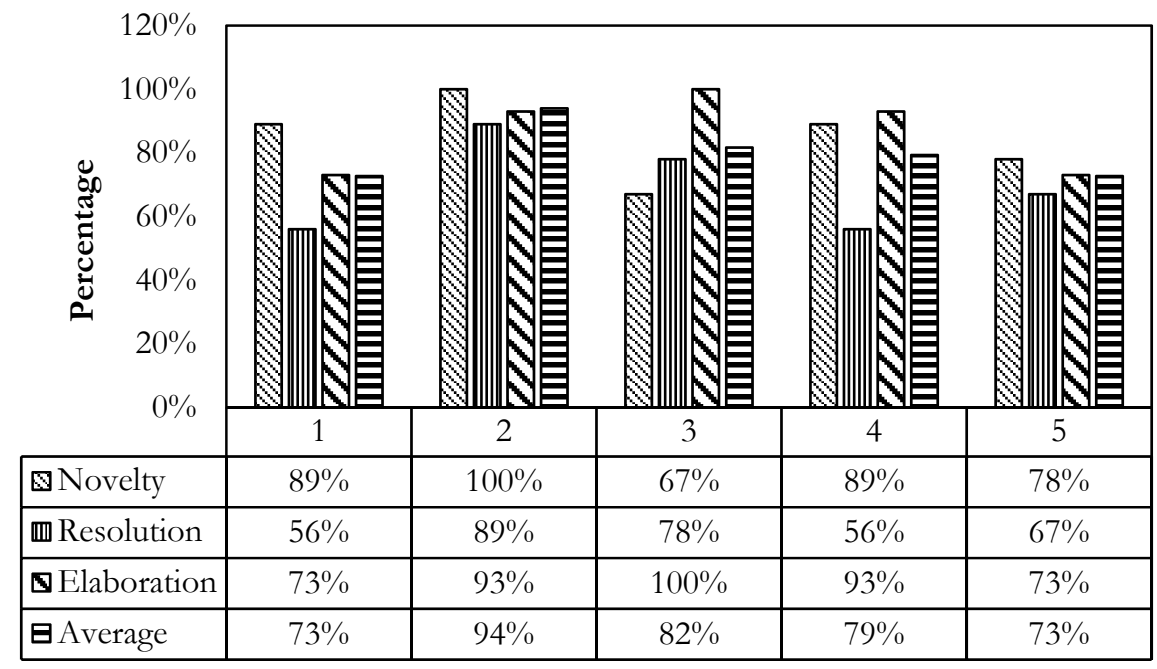

Dimension in Each Group

Figure 3 Result of creativity in each group

elaboration in average $94 \%$. Group 3 got $67 \%$ for novelty, $78 \%$ for resolution, and $100 \%$ for elaboration in average $82 \%$. Group 4 got $89 \%$ for novelty, $56 \%$ for resolution, and $93 \%$ for elaboration in average $79 \%$. The last, group 5 got $78 \%$ for novelty, $67 \%$ for resolution, and $73 \%$ for elaboration in average $73 \%$.

Creativity dimensions of a product consist of three aspects which are novelty, resolution, and elaboration and synthesis (Besemer, 2000). Each aspect has some criteria. The criteria of novelty are original, surprising, and germinal; for resolution are valuable, logic, and useful; for elaboration and synthesis are elegant, well-crafted, organic, complex, and understandable. Each criterion of creativity is used to assess students' creative product as the final result of STEAM-Based Learning implementation. Overall, the students' creative product is categorized as good (Henriksen, 2014).

This result is supported by research conducted by Kim, Ko, Han, and Hong (2014) that significant improvement was found in students' creativity by using STEAM-Based Learning compared to the control group. It happens because in STEAM-Based learning consist of the creative process in every step of the implementation. In line with the research of Kim, Chung, Woo, \& Lee (2012) that STEAM leads to processes that result in creativity, innovation, and continued growth and exploration of the world. Another research supported this result conducted by Kim, Ko, Han, and Hong (2014) that there is significant improvement found in the creativity and scientific interest in elementary students.

\subsection{The Relation between Student's Concept Mastery and Creativity}

In order to compare and relate the result of students' concept mastery and creativity, the charts of the comparison between student's concept mastery and creativity is made. The chart is shown in Figure 4.

The relation between students' concept mastery and creativity could be seen through the cognitive level of concept mastery and dimension of creativity. Here, the level of cognitive used was analyzing, evaluating, and creating. The dimension of creativity used here was novelty, resolution, and elaboration and synthesis. Anderson and Krathwohl (2001) stated that analyzing is finding, integrating, something, and organizing something or breaking material into its constituent parts and detecting how the parts relate to one another and to an overall structure or purpose. Evaluating is checking, critiquing, of testing something or making judgments based on criteria and standards. Creating is designing, constructing, planning, or making something or putting elements together to form a novel, coherent whole or make an original product. The dimension of creativity used here novelty, resolution, and elaboration and synthesis. Besemer and Treffinger (1981) stated that novelty is the newness of the product, new techniques, new process, and another element of newness. Resolution is how well the product does what it is supposed to do. Elaboration and synthesis consider product's presentation style.

There is a similarity between the cognitive level and the dimension of creativity. If we relate the level of cognitive and the dimensions of creativity, we can see that analyzing is closest to resolution. Both analyzing and resolution are to make something in order, relate to one another, and how something does what it is supposed to do. Evaluating is closest to elaboration and synthesis which is testing or judging something or product and how to describe it. Creating is closest to novelty which is constructing or making something new. 


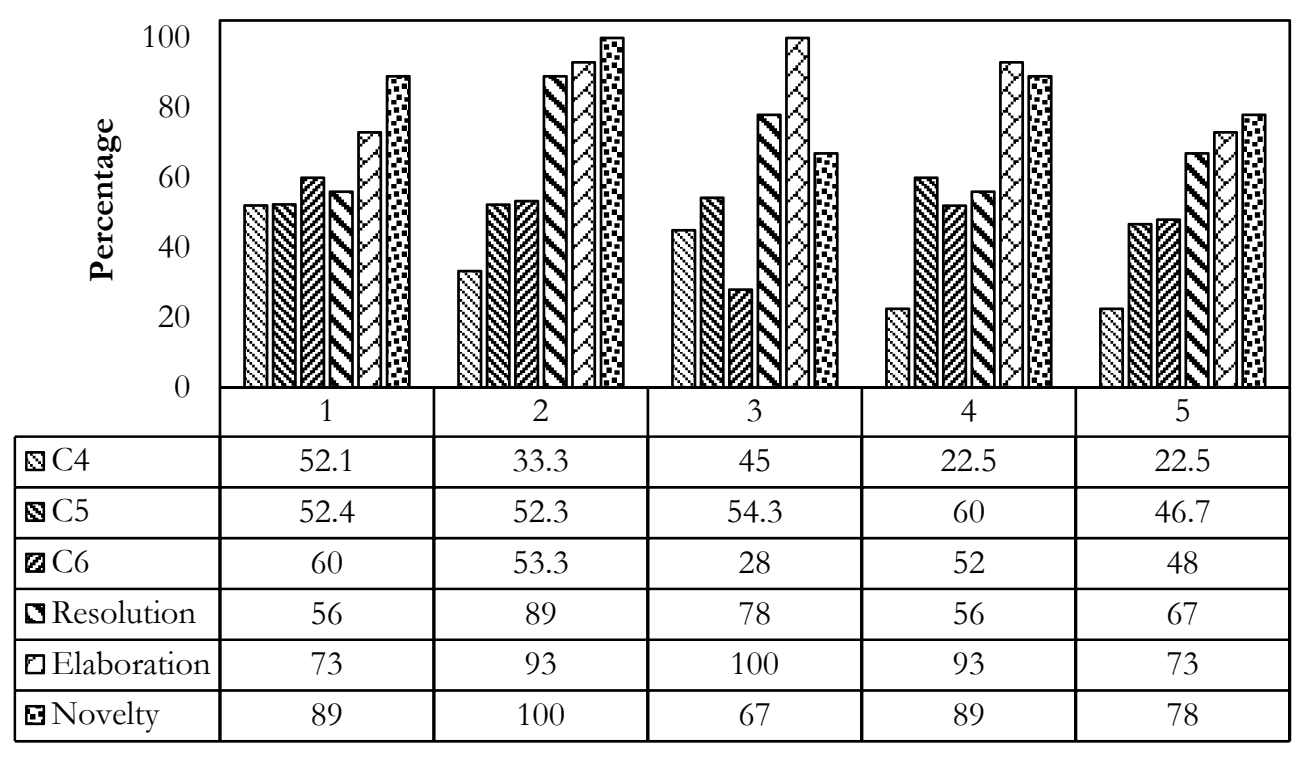

Group

Figure 4 Comparison between students' concept mastery and creativity

Based on the explanation, the students' concept mastery and creativity relate each other. It is proven with the pattern of the relationship between students' concept mastery and creativity result. The data of the students' concept mastery and creativity is shown in Figures 4. From the data, it is clear that every cognitive level paired with a dimension of creativity will be the same. The higher the value of $\mathrm{C} 4$, the novelty value will be high. as well as elaboration and C5 also resolution and $\mathrm{C} 4$. It also can be related also with the implementation of STEAM-Based Learning where the students more excited to prove something whether it is right or wrong and in the presentation session, they were so excited to explain the product. It is proven by Kim and Park (2012) stated that the STEAM improves the student understanding and interest. This condition is proven with the value both of evaluating and elaboration and synthesis are higher than other cognitive level and dimension of creativity. Different from the result of analyzing and novelty which gains the lowest value. The students are hard to analyze something and making the product different with the example given.

\section{CONCLUSION}

Based on the result of STEAM-Based Learning implementation that has been conducted, STEAM-Based Learning effect significantly to Students' Concept Mastery and Creativity in Learning Light and Optics. There are some other conclusions gained:

Implementation of STEAM-Based Learning on light and optics concept improves students' concept mastery. It can be noticed by the gain of pre-test and post-test score that is 0.78 which included as high improvement category.
Implementation of STEAM-Based Learning can be used to profile students' creativity through the project. Students' creativity is assessed based on CPSS rubric focuses on tree dimension which is novelty, resolution, and elaboration and synthesis. Students' creativity on novelty gain $76 \%$, on the resolution is $78 \%$, while on the elaboration and synthesis is $69 \%$. All creativity is categorized as good.

\section{ACKNOWLEDGMENT}

The authors acknowledge Mrs. Rika Rafikah for stimulating discussion about educational assessment.

\section{REFERENCES}

Anderson, L. W., \& Krathwohl, D. R. (2001). A Taxonomy for Learning, Teaching and Assessing (A Revision of Bloom's Taxonomy of Educational Objectives). United States: Addison Wesley Longan, Inc.

Baek, J.-E., \& Yoon, M.-B. (2016). Development and Application of STEAM Education Program Based on Robots: Through a ThemeBased Robot Soccer. International Journal of Computer Science and Information Technology for Education, 1(1), 27-34.

Besemer, S. P. (2000). Creative product analysis to foster innovation. Design Management Journal (Former Series), 11(4), 59-64.

Besemer, S. P., \& Treffinger, D. J. (1981). Analysis of creative products: Review and synthesis. The Journal of Creative Behavior, 15(3), 158-178.

Bloom, B. S. (1984). The 2 sigma problem: The search for methods of group instruction as effective as one-to-one tutoring. Educational researcher, 13(6), 4-16.

Creswell, J. W. (2012). Educational research: Planning, conducting, and evaluating quantitative and qualitative research. Educational Research (Vol. 4). United States: Pearson. https://doi.org/10.1017/CBO9781107415324.004

Fraenkel, J. R., Wallen, N. E., \& Hyun, H. H. (2011). How to design and evaluate research in education. New York: McGraw-Hill Humanities/Social Sciences/Languages.

Gurteen, D. (1998). Knowledge, creativity and innovation. Journal of knowledge Management, 2(1), 5-13. 
Hake, R. R. (1998). Interactive-engagement versus traditional methods: A six-thousand-student survey of mechanics test data for introductory physics courses. American journal of Physics, 66(1), 64 74.

Henriksen, D. (2014). Full STEAM ahead: Creativity in excellent STEM teaching practices. The STE $A M$ journal, 1(2), 15.

Henriksen, D., Mishra, P., \& Fisser, P. (2016). Infusing Creativity and Technology in 21st Century Education: A Systemic View for Change. Journal of Educational Technology \& Society, 19(3).

Kim, D. H., Ko, D. G., Han, M. J., \& Hong, S. H. (2014). The Effects of science lessons applying STEAM education program on the creativity and interest levels of elementary students. Journal of the Korean Association for Science Education, 34(1), 43-54.

Kim, S. W., Chung, Y. L., Woo, A. J., \& Lee, H. J. (2012). Development of a theoretical model for STEAM education. Journal of the Korean Association for Science Education, 32(2), 388-401.

Kim, Y., \& Park, N. (2012). Development and application of STEAM teaching model based on the Rube Goldberg's invention. In
Computer science and its applications (pp. 693-698). Springer, Dordrecht.

Kong, Y. T., \& Huo, S. (2014). An Effect of STEAM Activity Programs on Science Learning Interest. Advanced Science and Technology Letters, 59, 41-45.

O'Quin, K., \& Besemer, S. P. (2006). Using the creative product semantic scale as a metric for results-oriented business. Creativity and Innovation Management, 15(1), 34-44.

Pratiwi, W. N. W., Rochintaniawati, D., \& Agustin, R. R. (2018). The Effect of Multiple Intelligence-Based Learning Towards Students' Concept Mastery and Interest in Matter. Journal of Science Learning, $1(2), 49-52$.

Shidiq, A., Rochintaniawati, D., \& Sanjaya, Y. (2017). The Use of Self Construction Animation Learning Software to Improve the Students Concept Mastery on Structure and Functions of Plants. Pancaran Pendidikan, 6(3). 